\title{
Can apricot kernels fatty acids delay the atrophied hepatocytes from progression to fibrosis in dimethylnitrosamine (DMN)-induced liver injury in rats?
}

\author{
Manal K Abdel-Rahman
}

\begin{abstract}
Background and aims: The present study was aimed to analyze the chemical composition of ground apricot kernel (GAK) and examine its effect on hepatic fibrosis in vivo induced by dimethylnitrosamine (DMN) in rats.

Methods and results: Hepatic fibrosis was induced by intraperitoneal injections of $10 \mathrm{mg} / \mathrm{kg}$ DMN for 3 consecutive days each week over a period of $4 \mathrm{wk}$. The rats were randomly assigned to five groups of nine rats each: the negative control group (NC), the hepatic fibrosis group (PC), hepatic fibrosis supplemented with GAK (0.5 $\mathrm{mg} / \mathrm{kg} / \mathrm{BW} / \mathrm{rat})$, hepatic fibrosis supplemented with GAK (1 mg/kg/BW/rat) and hepatic fibrosis supplemented with GAK (1.5 mg/kg/BW/rat). Rats were killed, blood was collected and livers were excised for biochemical measurements and histological examination. Results indicate that the diet supplemented with GAK led to improving liver function, lipid peroxides, and liver CAT, SOD and GSH. These results were confirmed by liver histology. Hierarchically high levels f GAK (1.5 mg/kg/BW/rat) gave the best results compared to other tested levels.

Conclusion: This study demonstrates that GAK administration specifically $(1.5 \mathrm{mg} / \mathrm{kg} / \mathrm{BW} / \mathrm{rat})$ can effectively improve liver fibrosis caused by DMN, and may be used as a therapeutic option and preventive measure against hepatic fibrosis. Furthermore, a human trial would be applied specially GAK is a part of Egyptian diet. The act of why high amounts of GAK was improved biochemical values compared to low or moderate levels tested in this study may be due to increase levels of oleic acid and other polyphenols in apricot kernels
\end{abstract}

Keywords: Ground apricots kernel (GAK), Antioxidant activity, Cyanide, Dimethylnitrosamine, Liver fibrosis

\section{Introduction}

Apricot fruit is a part of Egyptian diet, is nutritionally contains carbohydrates, organic acids and mineral elements (iron, boron and potassium), vitamins such as pro-vitamin A, vitamins B, C and polyphenols $[1,2]$. Besides, phenolic compounds, such as quercetin, catechin, epicatechin, $p$-coumaric acid, caffeic acid, ferulic acid and their esters have been identified in the fruits [3]. Apricot kernel (AK) is traditionally roasting and mixing with coriander seeds and salt in a ground mixture called "Dokka" and eaten as part of Egyptian folk diet as a part of a meal or as a snack.

Correspondence: rahmanmk2002@yahoo.co.uk

Nutrition and Food Science Department, Faculty of Home Economics, Helwan University, Cairo, Egypt
Apricot kernels are generally exported to European countries and used especially in medicine, cosmetic and oil production [4]. Durmaz and Alpaslan [5] mentioned that apricot kernels are added to bakery products (as whole kernels or ground) in retail bakeries and also consumed as appetizers.

Apricot kernels, particularly rich in lipid and protein, are potentially useful in human nutrition [6,7] along with significant amounts of oil and fiber $[8,9]$. In a previous study, reported that sweet apricot kernels contain more oil than bitter kernels, and that oleic acid and linoleic acid correspond to approximately 92 $\mathrm{g} / 100 \mathrm{~g}$ of the total fatty acids present in apricot kernel Femenia et al. [6].

\section{Biomed Central}


Amygdalin(Figure 1) is a major component of apricot kernels, bitter almonds and peach, plum, pear and apple seeds [10]. The amount of cyanogenic glycosides in plants varies with plant species and environmental effects [10]. For example, apricot seeds and bitter almonds contain approximately 20-80 $\mu \mathrm{mol} / \mathrm{g}$ and 100 $\mu \mathrm{mol} / \mathrm{g}$ of amygdalin, respectively.

Amygdalin ( $D$-mandelonitrile- $\beta$-D-glucoside- $6-\beta$-glucoside) degrades to hydrogen cyanide, two molecules of glucose and benzaldehyde. Amygdalin hydrolysis is catalyzed by the enzyme emulsin, a $\beta$-glucosidase also found in apricot kernels. Since $\beta$-glucosidase enzymes do not occur intracellularly in humans, swallowing of whole apricot kernels may not release much cyanide [11], cyanogenetic glycosides may be essential for plant development and growth; the studies are represented by the work of [11]. However, the primary concern is their occurrence in food supplies and the potential adverse effects of long-term, low-level consumption. Cases of chronic cyanogen poisoning are documented in Third World areas, where cassava (Manihot aesculenta) that is a major food source [12].

After consumption of apricot and other fruit seeds, bitter almonds, cassava, or bamboo shoots, cyanide (CN) could be produced in high enough levels from the hydrolysis of amygdalin, and other cyanogenetic glycosides to pose a potential chronic toxicity problem $[13,14]$. These compounds may have evolved in plants as a chemical defense against grazing animals, as evidenced by the lethality of chokecherry leaves to livestock [15] and the apparent teratogenic effect of $P$. armenlaca in swine [16].

Liver injury is caused by different agents, such as viruses, chemicals, alcohol, and auto-immune diseases. It was pointed out that Dimethylnitrosamine (DMN) is a potent hepatotoxin that can cause fibrosis of the liver. At high doses, it is a "potent hepatotoxin that can cause fibrosis of the liver" in rats [17]. DMN is a potent hepatotoxin, carcinogen, and mutagen. DMN-induced liver

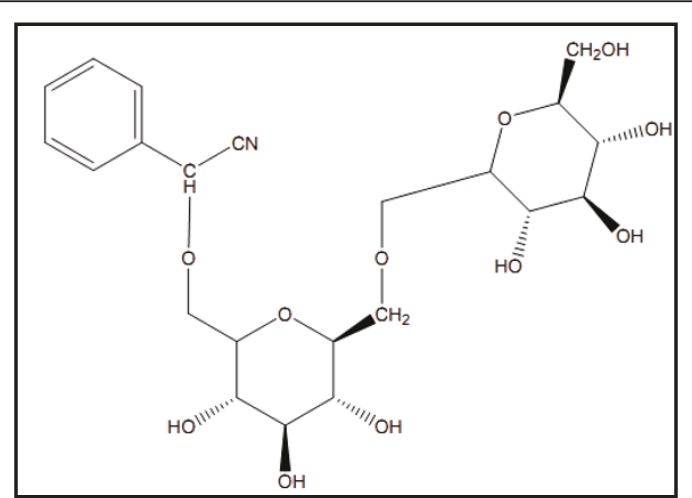

Figure 1 The chemical structure of amygdalin. injury in rats seems to be a good animal model for early liver cirrhosis [17]. A model of cirrhosis induced by chronic, discontinuous treatment with a low dose of $\mathrm{DMN}$ in the rat has been reported to reproduce a number of characteristics of this liver disease [18]. The extent of liver injury can be easily estimated by measuring the activities of certain plasma enzymes, e.g., alanine aminotransferase (ALT) and aspartate aminotransferase (AST).

Hepatic fibrosis is a common result of chronic injury to the liver [19]. Hepatic fibrosis is a consequence of severe liver damage and occurs in many forms of chronic liver damage, including virus infection, autoimmune liver diseases and sustained alcohol abuse [20]. However, the hepatoprotective effect of apricot kernel in dimethylnitrosamine (DMN)-induced models has rarely studied. The DMN-induced liver fibrosis model can reproduce most of the features observed during human liver fibrosis [21]. Furthermore, this model has other advantages such as progressive and remarkable pathological alterations, a high fibrosis reproduction rate, and a low mortality rate in experimental animals [22]. This model is also stable even after termination of DMN administration and is a reliable tool for screening antifibrotic agents [17]. Therefore, the aim of the present study was to examine the effect of ground apricot kernel (GAK) on hepatic fibrosis in rats.

\section{Materials and methods}

\subsection{Materials}

Dimethylnitrosamine (DMN) and all reagents and chemicals were purchased from El-Gomhorya Company, Cairo, Egypt.

Kits used to determine biochemical factors in serum were obtained from Egyptian American Company for Laboratory Service and Supplied by Alkan Company.

\section{Apricot kernel}

Apricots (Prunus armeniaca L.) was purchased from local fruit market (Giza-Egypt, June 2010). Apricot flesh was removed from fruits; the apricot outer shell was washed with tap water and air-dried at $30^{\circ} \mathrm{C}$ for about 2 weeks the outer shell of apricot was cracked manually and the edible part (kernel) was stored at $-20^{\circ} \mathrm{C}$ in sealed plastic bags until used. The apricot kernels were soaked in warm distilled water for $1 \mathrm{~h}$, kernel thin layer coat was removed manually. The apricot kernels were placed on a sheet of filter paper and dried under fume cupboard for $2 \mathrm{~h}$ and ground in a coffee machine for 1 min. The ground apricot kernels (GAK) were identified in the proximate analyses. In order to prevent the ground apricot kernel (GAK) from possible rancidity and oxidation that may occur during storage, the (GAK) was prepared freshly within $1 \mathrm{~h}$ before adding to basal diet. 


\section{Detoxification of apricot kernels}

Detoxification of apricot kernels (AK) was conducted by soaking AK [23] in distilled water and ammonium hydroxide for $30 \mathrm{~h}$ at $47^{\circ} \mathrm{C}$ in order to decrease the total protein, non-protein nitrogen, total ash, glucose, sucrose, minerals, non-essential amino acids, polar amino acids, acidic amino acids, aromatic amino acids, anti-nutritional factors, hydrocyanic acid, tannins and phytic acid. On the other hand, remove toxic and bitter compounds from $\mathrm{AK}$, increased the relative content of crude fiber, starch, and total essential amino acids.

\subsection{Methods}

\section{Determination of total phenolics in GAK}

A size of half gram of GAK were extracted in $50 \mathrm{~mL}$ of $62.5 \%$ aqueous methanol at $40^{\circ} \mathrm{C}$ for $2 \mathrm{~h}$. Extracts were used promptly for analysis (in order to avoid any loss in polyphenols content as reported in [3]. Total phenolics were measured according to Waterman and Mole [24] using Folin-Ciocalteu assay. The Folin-Ciocalteu assay detects phenolics via oxidation of the phenol ion by a phosphotungstic-phosphomolybdic complex, resulting in blue coloration of the reduced chromophore. Fifteen microlitres of extract were added to $1.85 \mathrm{~mL}$ of deionized $\mathrm{H}_{2} \mathrm{O}$ and $75 \mu \mathrm{L}$ of Folin-Ciocalteu reagent (Sigma Chemical Co., Cairo, Egypt), followed by adding $225 \mu \mathrm{L}$ sodium carbonate after $5 \mathrm{~min}$. After $2 \mathrm{~h}$ incubation at room temperature, absorbance of the solution at $760 \mathrm{~nm}$ was measured using a Helios Gamma Spectrophotometer (Unicam, Cambridge, UK), and compared with that of a condensed tannin standard (Sigma Chemical Co., Cairo, Egypt).

\section{Determination of cyanide}

Apricot kernels were obtained manually from apricot fruit and assayed for cyanide $(\mathrm{CN})$ content by the method of Haque and Bradbury [25]. Amygdalin was determined as follows, $100 \mathrm{ml}$ of $1 \mathrm{~g} \mathrm{HCN}$ equivalents/ 1 solutions were added to $0.1 \mathrm{M}$ phosphoric acid and made up to $25 \mathrm{ml}$ in a standard flask. Standard solutions of $1.00 \mathrm{~g} \mathrm{HCN}$ equivalents/l of $\mathrm{KCN}$ and acetone cyanohydrin were prepared and added to $0.1 \mathrm{M}$ phosphoric acid. To duplicate aliquots $(2.00 \mathrm{ml})$ of these solutions was added $2.0 \mathrm{ml}$ of $4 \mathrm{M}$ sulphuric acid and the mixture heated for different times in a B14 stopper test tube in a boiling water bath, which just covered the liquid level in the test tube. Each sample was cooled in ice cold water, with the stopper loosely in place, $5.0 \mathrm{ml}$ of $3.6 \mathrm{M}$ sodium hydroxide was added and after $5 \mathrm{~min}, 1 \mathrm{ml}$ was placed to $7 \mathrm{ml}$ of $0.2 \mathrm{M}$ acetate buffer at $\mathrm{pH}$ 5.0. Chloramine-T $(0.4 \mathrm{ml}), 5 \mathrm{~min}$ later $1.6 \mathrm{ml}$ of isonicotinic acid/barbituric acid was added. After one hour, the absorbance was measured at $600 \mathrm{~nm}$ [26]. A calibration curve was obtained using a standard solution of $\mathrm{KCN}$ [26]. The amount of total cyanide present was obtained by linear extrapolation to zero time of the data. Ten replicate analyses were made in duplicate with amygdalin with linear extrapolation to zero time. Finely ground material (usually 100 mg) from GAK, was taken immediately after grinding and made up to $10.0 \mathrm{ml}$ with $0.1 \mathrm{M}$ phosphoric acid. The mixture was centrifuged and duplicate $2.00 \mathrm{ml}$ taken for analysis as described above. The total cyanide content was obtained by linear extrapolation to zero time.

\section{Proximate Analyses}

The moisture content was determined by heating two grams of ground apricot kernel air-dried sample in a vacuum oven at $700^{\circ} \mathrm{C}$ under pressure of $95 \mathrm{mmHg}$ to a constant weight [27]. The crude fat content was determined as follows: the oven-dried samples obtained from the moisture content determination was then extracted with petroleum ether $\left(60-800^{\circ} \mathrm{C}\right)$ for 16 hours in Soxhlet-type extractor. The ether was evaporated and the residue dried to a constant weight at $95-1000^{\circ} \mathrm{C}$ and then cooled in a desiccator. The weight loss expressed as percentage gave the crude fat content [28].

The nitrogen percentage was determined by the improved Kjeldahl method described in AOAC [28] and the nitrogen content was converted to crude protein by multiplying with 6.25 [27]. The ceramic fiber filter method as described in AOAC [28] was used to analyze the crude fiber content. Briefly, two grams ground sample was defatted with petroleum ether then digested with $1.25 \%(\mathrm{v} / \mathrm{v}) \mathrm{H}_{2} \mathrm{SO}_{4}$ and $1.25 \%(\mathrm{v} / \mathrm{v}) \mathrm{NaOH}$. The residues were ignited at $1300^{\circ} \mathrm{C}$ for 2 hours, cooled in a desiccator and weighed. The ash content was determined using AOAC recommended method [28]. The carbohydrate content of the sample was determined by subtracting the sum of the percentages of moisture, crude fat, fiber, protein and ash from 100.

Rats

Rats were purchased from the laboratory animal colony, Ministry of Health and Population, Helwan, Cairo, Egypt.

\section{Experimental design}

The animal experiment was conducted and approved according to the institutional guidelines of Ophthalmology Institute Guide Care of Animals (Giza-Egypt). Forty five males Sprague-Dawley rats weighing (200 $\pm 5 \mathrm{~g}$ ) were kept in individual stainless steel cages under hygienic condition and were fed on basal diet for one week for adaptation according to Ain-93 [29]. After a period of adaptation, the rats were randomly assigned to five groups of nine rats each as follows:

Group I: fed on basal diet and used as a negative control group (NC).

Group II: injected with DMN and fed on basal diet, used as a positive control group (PC). 
Group III: injected with DMN and fed on basal diet containing ground apricot kernel (GAK) in amount of $0.5 \mathrm{mg} / \mathrm{kg}$ body weight $/ \mathrm{rat}$.

Group IV: injected with DMN and fed on basal diet containing ground apricot kernel (GAK) in amount of $1.0 \mathrm{mg} / \mathrm{kg}$ body weight $/ \mathrm{rat}$.

Group V: injected with DMN and fed on basal diet containing ground apricot kernel (GAK) in amount of $1.5 \mathrm{mg} / \mathrm{kg}$ body weight $/ \mathrm{rat}$.

\section{Inducing hepatic fibrosis in rats}

Hepatic fibrosis was induced by intraperitoneal of dimethylnitrosamine (DMN) injected to the animals based on $10 \mathrm{mg} / \mathrm{kg}$ for 3 consecutive days each week over a period of $4 \mathrm{wk}$ according to Asakura et al, [30]. During the experimental period (4 weeks), diet consumed and body weights for rats were recorded twice a week and liver index, which is calculated as percent of liver weight at final body weight [31].

\section{Biochemical analyses in the serum}

At completion of the experiment, the animals were fasted overnight, anaesthetized with $\mathrm{CO}_{2}$ and sacrificed to obtain blood samples. Each blood sample was placed in dry clean centrifuge tube, and then centrifuged at $950 \mathrm{xg}$ for $20 \mathrm{~min}$. at $4^{\circ} \mathrm{C}$ to separate the serum. Serum was carefully separated into clean dry Wassermann tubes by using a Pasteur pipette and kept frozen at $-20^{\circ} \mathrm{C}$ until analyses.

The liver was separated from each rat then washed thoroughly in ice-cold physiological saline $[0.9 \%(\mathrm{w} / \mathrm{v}) \mathrm{NaCl}]$, and weighed to calculate liver to body weight percentage.

Hepatotoxicity was assessed by quantifying the activities of serum alanine aminotransferase (ALT) and aspartate aminotransferase (AST), according to [32]. Superoxide dismutase (SOD) content was determined by the xanthine oxidase method.

\section{Thiobarbituric acid-reactive substances (TBARS)}

The content of serum lipid peroxides was analyzed by using thiobarbituric acid-reactive substances (TBARS) and expressing them as malonaldehyde equivalents using the method of Yagi [33] with reduced proportions. In brief, $20 \mu \mathrm{L}$ serum was added to $2 \mathrm{~mL} 40 \mathrm{mmol} / \mathrm{L}$ $\mathrm{H}_{2} \mathrm{SO}_{4}$ (Sigma Pharmaceutical Industries, Cairo, Egypt), then $0.25 \mathrm{~mL} \mathrm{10 \%} \mathrm{wt/vol} \mathrm{phosphotungstic} \mathrm{acid} \mathrm{(Sigma}$ Chemical Co. Cairo, Egypt) was added and mixed. The mixture was centrifuged at $950 \mathrm{xg}$ for $15 \mathrm{~min}$., the supernatant was discarded, and the sediment was mixed with $1 \mathrm{~mL} 40 \mathrm{mmol} / \mathrm{L} \mathrm{H}_{2} \mathrm{SO}_{4}$ and $0.15 \mathrm{~mL} \mathrm{10 \%} \mathrm{wt/vol}$ phosphotungstic acid. The mixture was centrifuged at $950 \mathrm{xg}$ for another $15 \mathrm{~min}$. The sediment was suspended in $2 \mathrm{~mL}$ distilled water, and $0.5 \mathrm{~mL} 0.33 \%$ wt/ vol thiobarbituric acid reagent (Sigma Pharmaceutical Industries, Egypt) was added. The mixture was heated for 60 minutes at $95^{\circ} \mathrm{C}$ in a water bath, then $2.5 \mathrm{~mL} n$ butanol (Sigma Pharmaceutical Industries, Egypt) was added and the mixture was vigorously shaken. The butanol layer was taken after centrifugation at $950 \mathrm{xg}$ for 15 minutes and absorbance was taken for fluorometric measurement at $553 \mathrm{~nm}$ with $515-\mathrm{nm}$ excitation.

\section{Biochemical analyses in liver tissues}

Liver catalase (CAT) was determined by Goth's colorimetric method, in which supernatant was incubated in $\mathrm{H}_{2} \mathrm{O}_{2}$ substrate and the enzymatic reaction was stopped by the addition of ammonium molybdate. The intensity of the yellow complex formed by molybdate and $\mathrm{H}_{2} \mathrm{O}_{2}$ was measured at $405 \mathrm{~nm}$ [34].

Superoxide dismutase (SOD) activity was determined by using a measurement method developed by McCord and Fridovich [35]. This method is based on the generation of superoxide radicals produced by xanthenes and xanthenes oxidase, which react with 2-(4-iodophenyl)-3(4-nitrophenol)-5-phenyltetrazolium chloride (INT) to form a red formazan dye. SOD activity was expressed as units per gram protein.

Glutathione peroxidase (GSH-Px) activity was measured on standard assay conditions in $340 \mathrm{~nm}$ (absorbance) at $37^{\circ} \mathrm{C}$ according to the method developed by Paglia and Valentine [36]. In this measurement, GSH-Px catalyzes the oxidation of glutathione by cumene hydroperoxide. Measurements were performed by an autoanalyzer (Biochemistry Dept., Faculty of Veterinary Laboratories, Cairo University) according to the Randox application procedure. GSH-Px activity was expressed as units per gram protein.

\section{Histopathological studies}

Specimens from left liver lobe were fixed in $10 \%$ formalin solution for $24 \mathrm{~h}$, the fixed specimens were then trimmed, washed and dehydrated in bedded in paraffin, cut in sections of 46 microns thickness and stained with haematoxylin and eosin stain [37] and assessed in a light microscope (Nikon Eclipse E400). All alterations from the normal structure were registered. The following criteria were used for scoring liver histology; (0) indicates to no histopathological changes were observed and from 1-4 indicates to different degrees from histopathological changes that increase in numbers along with severity; for example 4 indicates to severe changes, 3 moderate, 2 mild and 1 slight changes.

\section{Statistical analysis}

The data analysis was carried out with SPSS Inc. software (version 15.0). One-way ANOVA was used to study a significant difference between means of the dietary groups with a significance level of $\mathrm{P}<0.05$. Duncan's test was used to compare the significance among the rat groups. All data are presented as \pm standard deviation of means (STD) [38].

\section{Results}

The chemical composition of ground Apricot Kernels (GAK) 
Results from (Table 1) indicate to the mean values of protein, carbohydrates, fiber, total polyphenols and cyanide in GAK.

The distribution of fatty acids composition in GAK is given in (Table 2) The dietary GAK was rich in oleic (74.59\%) acids, while linoleic acid represent (19.57\%), with stearic, palmitic, palmitoleic and arachidic acids constituting $0.96 \%, 4.11 \%, 0.59 \%$, and $0.18 \%$ respectively.

\section{Biochemical results}

As shown in (Table 3) the liver index, (the percent of liver weight to final body weight), was significantly different among the experimental groups. Liver index was decreased in rat groups compared to negative control (NC).

AST and ALT concentrations in serum were used as biochemical markers to evaluate hepatic injury. ALT is a cytosolic enzyme, primarily present in the liver. An increase in serum ALT indicates liver damage more specifically than AST. AST, which is a mitochondrial enzyme present in large quantities in the heart, liver, skeletal muscle, and kidney, in part indicates liver injury. Serum activities of ALT and AST were found to be significantly increased in DMN group when compared with $\mathrm{NC}$ group $(\mathrm{p}<0.05)$. A significant increase of the liver enzymes in the serum was occurred after dimethylnitrosamine (DMN) administration alone, which was significantly lowered by presence of GAK in III, IV and V rat groups $(\mathrm{p}<0.05)$ (Table 4$)$.

The value of MDA in the serum were decreased ( $\mathrm{p}$ 0.05 ) by the treatment of III, IV and V than that of the administration with DMN. The values of the activities of CAT and SOD in the liver tissue were increased ( $\mathrm{p}<$ 0.05 ) with the addition of GAK among rat groups; III, $\mathrm{IV}$ and $\mathrm{V}$ compared to PC group (Figure 2).

\section{Histopathological results}

Representative figures of hematoxylin and eosin-stained sections of liver tissue from NC group (I) (Figure 3) were evaluated as a normal histology. Effects of ground apricot kernel (GAK) on liver tissue morphology in DMN-induced fibrosis model was shown as follows; DMN-injected (PC) (Figure 4,5), DMN-injected + GAK (0.5 mg/kg/BW/rat). DMN-injected + GAK (1 mg/kg/ $\mathrm{BW} /$ rat $)$ and DMN-injected + GAK (1.5 mg/kg/BW/rat).
Table 2 GLC Fatty acids composition in GAK analysis\%

\begin{tabular}{ll}
\hline OLEIC ACID (C18:1) & $74.59 \%$ \\
\hline Linoleic acid (C18:2) & $19.57 \%$ \\
\hline Stearic acid (C18:0) & $0.96 \%$ \\
\hline Palmitic acid (C16:0) & $4.11 \%$ \\
\hline Palmitoleic acid(C16:1) & $0.59 \%$ \\
\hline Arachidonic acid (C20:4) & $0.18 \%$ \\
\hline
\end{tabular}

The NC showed normal architecture, whereas PC (II) (Figure 4, 5) showed atrophied hepatocytes, dilatation and congestion of hepatic sinusoids and atrophy of hepatocytes and pyknosis of their nuclei due to toxicity from DMN. Sections III (Figure 6), IV (Figure 7) and V (Figure 8,9 ) showed a marked little decrease in the severity of hepatocellular necrosis compared to PC.

\section{Discussions}

In the present study, we focused our attention on the quantity of apricot kernel that showed an effective role in alleviating DMN-induced liver injury. For this purpose, GAK was separated into three levels in terms of amount added to the rats' diet and the effect of each level was investigated.

In this study, results showed that the treatment of rats' diet with ground apricot kernel (GAK) markedly inhibited acute hepatocellular injury in DMN model of liver toxicity. As reported previously, the initial step in liver injury caused by dimethylnitrosamine (DMN) is producing centrilobular necrosis of fairly rapid onset $[39,40]$.

\section{Chemical analyses of GAK}

The chemical composition of GAK indicates to high levels of oleic acid were found in GAK. It contains a substantial amount of dietary protein [41], along with significant amounts of oil and a fiber $[8,9]$. The result of the present study was in agreement with Montgomery [13] in the analysis of the chemical composition of GAK. In a study carried out by [13] demonstrates that dietary apricot kernel has preventive effects on $D$-galactosamine-induced liver injury. These results suggest that a prevention effect of liver injury that may be one of the important physiological property of dietary supplementation of the diet with apricot kernel. Similarly our

Table 1 Analysis of ground apricot kernels (GAK)

\begin{tabular}{|c|c|c|c|c|c|}
\hline $\begin{array}{l}\text { Protein } \\
\text { (g) }\end{array}$ & $\begin{array}{c}\mathrm{CHO} \\
(\mathrm{g})\end{array}$ & $\begin{array}{c}\text { Fiber } \\
\text { (g) (Units } / 100 \mathrm{~g})\end{array}$ & $\begin{array}{l}\text { Fat } \\
\text { (g) }\end{array}$ & $\begin{array}{c}\text { Total Phenolics } \\
(\mathrm{mg} / \mathrm{g})\end{array}$ & $\begin{array}{c}\text { Cyanide } \\
\text { (ppm) }\end{array}$ \\
\hline $16.04 \pm 3.5$ & $22.55 \pm 6.5$ & $4.29 \pm 6.3$ & $57.12 \pm 2.4$ & $2.5 \pm 1.9$ & 600 \\
\hline
\end{tabular}

All values are the mean of 3 measurements, $( \pm$ STD) 
Table 3 Relative organ weight in rats with DMN-induced hepatic fibrosis

\begin{tabular}{lc}
\hline Groups & Liver index \\
\hline I & $3.1 \pm 0.5^{\mathrm{d}}$ \\
\hline II & $2.6 \pm 0.4^{\mathrm{a}}$ \\
\hline III & $2.7 \pm 0.3^{\mathrm{b}}$ \\
\hline IV & $2.9 \pm 0.4^{\mathrm{e}}$ \\
\hline V & $3.0 \pm 0.1^{\mathrm{c}}$
\end{tabular}

Group I: fed on basal diet as a negative control group (NC). Group II: injected with DMN and fed on basal, used as a positive control group (PC). Group III: injected with DMN and fed on basal diet containing (ground apricot kernel)in amount of $0.5 \mathrm{mg} / \mathrm{kg}$ of body weigh/rat. Group IV: injected with DMN and fed on basal diet containing (ground apricot kernel) in amount of $1 \mathrm{mg} / \mathrm{kg}$ of body weigh/rat Group V: injected with DMN and fed on basal diet containing (ground apricot kernel) in amount of $1.5 \mathrm{mg} / \mathrm{kg}$ of body weigh/rat Values which don't share the same letter in each column are significantly different. Significance at $\mathrm{P}<0.05$, Liver index: Liver weight/body weight multiplied by 100 .

study has revealed to the improvement effect of GAK in terms of biochemical and histological results.

It would be suggested that the chemical composition of ground kernel apricot has a role in these changes; $[7,42]$ reported that oil content of kernels varies from 27.7 to $66.7 \%$, majority of fatty acids being oleic (58.3$73.4 \%)$ and linoleic acids (18.8-31.7\%). This component of monounsaturated fatty acid in apricot kernel was similar to olive oil content. That may be indicating the preventive role of apricot kernel from heart disease. Femenia et al [6] reported that sweet apricot kernels contain more oil than bitter kernels, and that oleic acid and linoleic acid correspond to approximately $92 \mathrm{~g} / 100$ $\mathrm{g}$ of the total fatty acids present. Similar results were found in the fatty acid composition of GAK.

The role of dietary antioxidants has also reported to protect from DMN toxicity; for example, potential physiologic activity of dietary flavonoids has often been the center of interest [43]. Phytosterols have been reported

Table 4 Effect of different levels of GAK on liver functions in serum with DMN induced hepatic fibrosis in rats $(\boldsymbol{n}=9)$

\begin{tabular}{cccc}
\hline Rat groups & AST (IU/mL) & ALT (IU/mL) & MDA ( $\mu \mathrm{mol})$ \\
\hline I & $85 \pm 2.1^{\mathrm{a}}$ & $243 \pm 2.6^{\mathrm{a}}$ & $2.30 \pm 2.8^{\mathrm{a}}$ \\
\hline II & $451.2 \pm 2.3^{\mathrm{b}}$ & $582 \pm 8.3^{\mathrm{b}}$ & $2.97 \pm 2.3^{\mathrm{b}}$ \\
\hline III & $261 \pm 2.8^{\mathrm{c}}$ & $446 \pm 2.7^{\mathrm{c}}$ & $2.48 \pm 1.5^{\mathrm{c}}$ \\
\hline IV & $224 \pm 2.4^{\mathrm{d}}$ & $312 \pm 2.9^{\mathrm{d}}$ & $2.53 \pm 3.1^{\mathrm{c}}$ \\
\hline V & $217 \pm 4.7^{\mathrm{d}}$ & $289 \pm 4.1^{\mathrm{d}}$ & $2.29 \pm 2.1^{\mathrm{a}}$ \\
\hline
\end{tabular}

Group I: fed on basal diet as a negative control group (NC). Group II: injected with DMN and fed on basal, used as a positive control group (PC). Group III: injected with DMN and fed on basal diet containing (ground apricot kernel) in amount of $0.5 \mathrm{mg} / \mathrm{kg}$ of body weigh/rat. Group IV: injected with DMN and fed on basal diet containing (ground apricot kernel) in amount of $1 \mathrm{mg} / \mathrm{kg}$ of body weigh/rat Group V: injected with DMN and fed on basal diet containing (ground apricot kernel) in amount of $1.5 \mathrm{mg} / \mathrm{kg}$ of body weigh/rat Values which don't share the same letter in each column are significantly different. Significance at $\mathrm{P}<0.05( \pm \mathrm{SD})$. in measurable amounts in over 250 plants [44]. These compounds have a similar structure to cholesterol but with some modifications to the side chain, including the addition of a double bond and/or methyl or ethyl group. Interest in phytosterols has centered on their cholesterol lowering properties thereby offering protection from cardiovascular disease [45].

There are several reasons that may explain the potential effect of GAK to improve DMN liver toxicity; cultivars of apricot, presence of toxic cyanogenic glycoside amygdalin that alleviate the effect of DMN [46] or the nutritional value of GAK that analyzed in this study and other studies indicating to the presence of high amount of oleic acid and polyphenolics. Interestingly, Amygdalin can be hydrolyzed to form glucose, benzaldehyde and hydrocyanic acid also enzymatic release of cyanide occurs in the presence of $\beta$-glucoronidase, an enzyme found in the human intestine [47].

The antioxidant system involves both enzymatic and non-enzymatic agents. The first step in the enzymatic system is superoxide dismutase (SOD), which catalyzes the dismutation of superoxide anion $\left(\mathrm{O}_{2}\right)$ to $\mathrm{H}_{2} \mathrm{O}_{2}$. The conversion of $\mathrm{H}_{2} \mathrm{O}_{2}$ to $\mathrm{H}_{2} \mathrm{O}$ by either glutathione peroxidase (GPx) or catalase forms the second step of enzymatic system. Superoxide dismutase and GPx enzyme activities and the balance between them are very crucial for protection against oxidative stress $[48,49]$. The values of the activities of CAT and SOD in the liver tissue were enhanced by the presence of GAK for III, IV and $\mathrm{V}$ rat groups than that of the PC group (Figure 2).

Among all bimolecular, lipids are the most sensitive molecules to free radical attacks. Double bonds in fatty acids form peroxide products by reacting with free radicals, and products [namely malonaldehyde (MDA) can be formed in cell membranes]. Malonaldehyde shows both mutagenic and carcinogenic effects by changing membrane properties [50,51]. In our study, the results of malonaldehyde indicated that the supplementation of diet with different levels of GAK would alleviate the toxicity of DMN in rats. The value of MDA in the serum was decreased when supplementing rats' diets with GAK among III, IV and V rat groups compared to PC.

As a result of the degradation of lipid peroxides, MDA forms and is used as an indicator of lipid peroxidation [51]. Halliwel and Chirico [52] demonstrated the higher stability of saturated and monounsaturated oils in lipid peroxidation than that of polyunsaturated fatty acids because there is no conjugated sites in these fatty acids for oxidation. There are numerous harmful effects of MDA reported [53,54]. Cross linking with the membrane components, MDA causes inactivation of enzymes and receptors in membranes and thus changes 


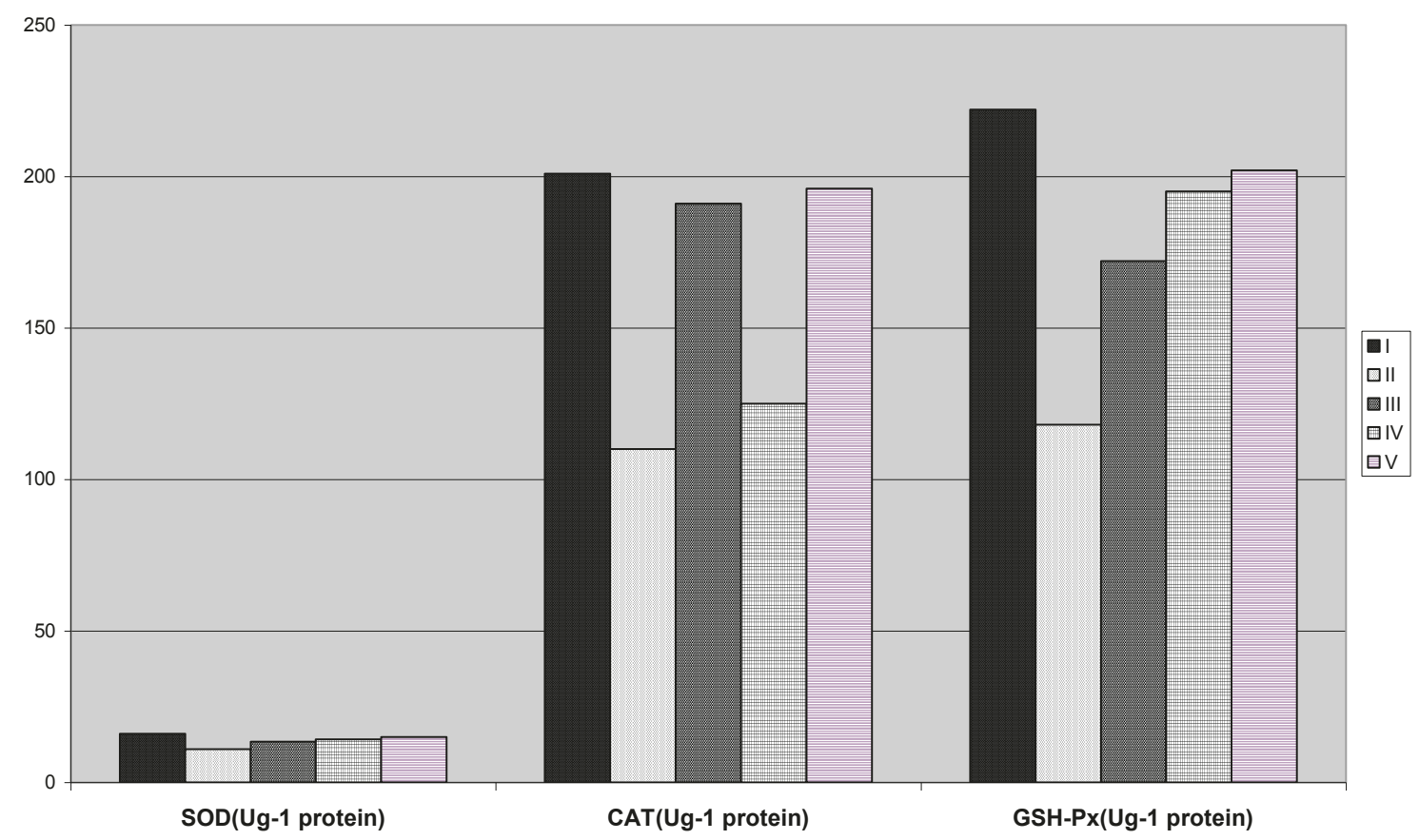

Figure 2 Effect of feeding apricot kernels on SOD, CAT and GSH. Group I: fed on basal diet as a negative control group (NC). Group II: injected with DMN and fed on basal, used as a positive control group (PC). Group III: injected with DMN and fed on basal diet containing (ground apricot kernel) in amount of $0.5 \mathrm{mg} / \mathrm{kg}$ of body weigh/rat. Group IV: injected with DMN and fed on basal diet containing (ground apricot kernel) in amount of $1 \mathrm{mg} / \mathrm{kg}$ of body weigh/rat Group V: injected with DMN and fed on basal diet containing (ground apricot kernel) in amount of $1.5 \mathrm{mg} / \mathrm{kg}$ of body weigh/rat Values which don't share the same letter in each column are significantly different. Significance at $\mathrm{P}<$ 0.05 .

membrane properties. Malondialdehyde also causes mutations by reacting with guanine nucleotide in DNA [55].

CAT is a hemoprotein, localized in the peroxisomes and catalyzes the decomposition of $\mathrm{H}_{2} \mathrm{O}_{2}$ to water and oxygen. GPx is a selenoenzyme, present predominantly in liver and catalyses the reaction of hydroperoxides with reduced glutathione to form glutathione disulphide (GSSG) and the reduction product of the hydroperoxide

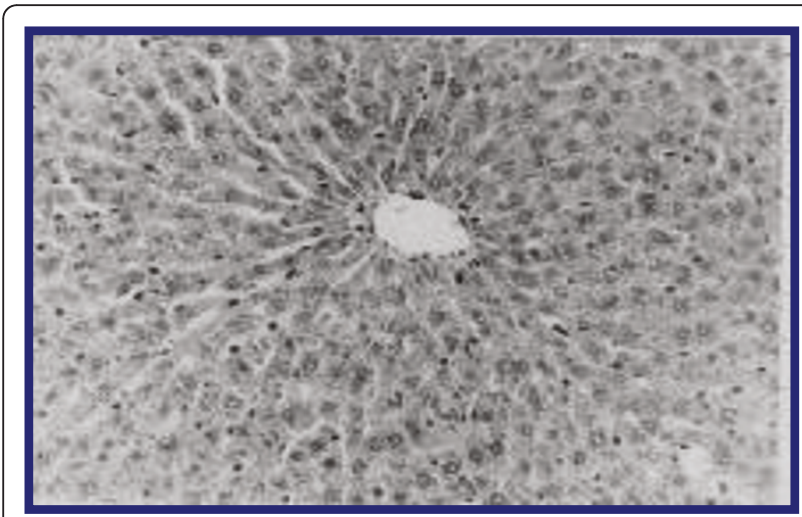

Figure 3 liver of rats of control group showing no histopathological signs (Hand EX 200) (Grade 0).
[56]. Increased activity of these antioxidant enzymes results in decreased formation of hydroxyl radical [57].

In the present study, the activity of SOD, CAT and GSH in the liver intoxicated with DMN (PC) - was significantly $(p<0.05)$ decreased compared to NC group. The activities of these enzymes in the liver intoxicated

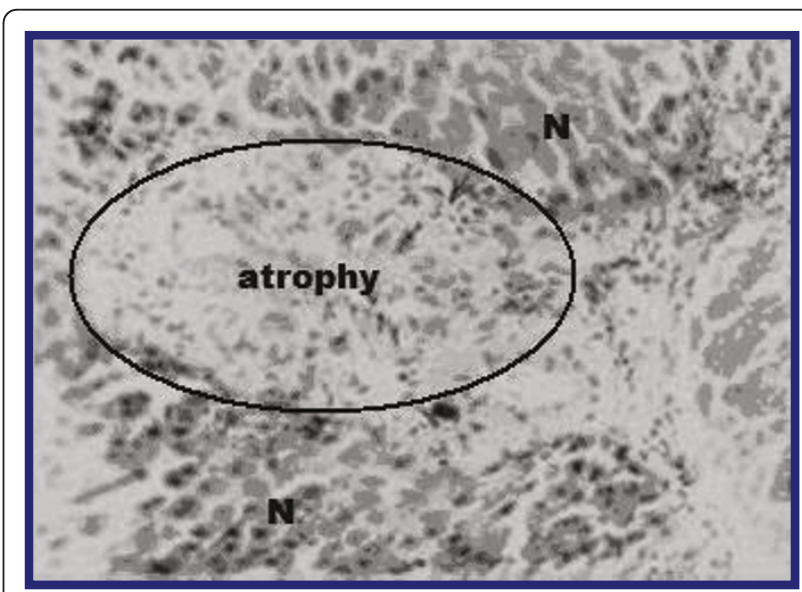

Figure 4 liver of rat DMN-injected (II). The encircled area shows atrophied hepatocytes due to toxicity from DMN. The surrounding tissue looks normal (grade 4). 


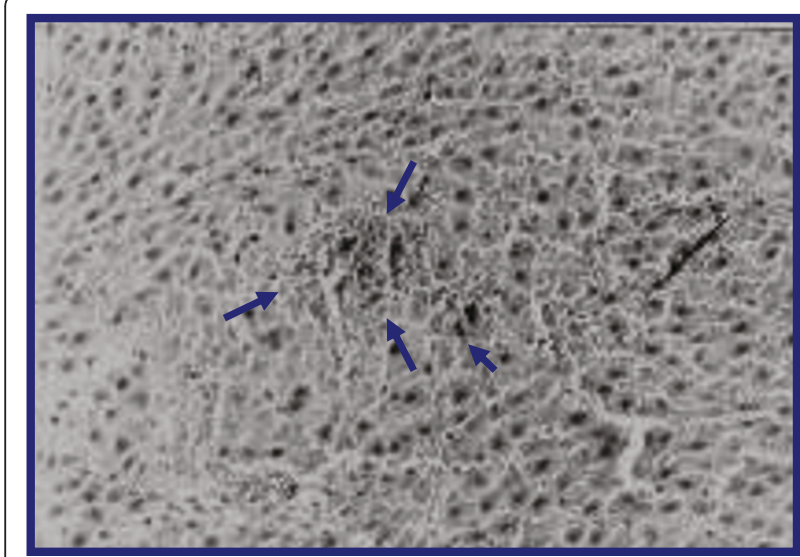

Figure 5 (Another section) liver of rat DMN-injected (II) shows marked dilatation and congestion of hepatic simunsoids (small arrows) atrophy of hepatocytes and pylnosis of their nuclei (large arrows) (Grade 4).

with DMN - (III, IV and V groups) were significantly ( $p$ $<0.05$ ) increased compared to PC group (Figure 2).

In this study, GAK administration prevented the development of hepatic fibrosis in a rat model of DMNinduced liver fibrosis at level of $1.5 \mathrm{mg} / \mathrm{kg} / \mathrm{BW} / \mathrm{rat}$. These results were confirmed both by liver histology and biochemical analyses.

Because GAK can be consumed over long periods of time as traditional habits, in the present study apricot kernel possessed a therapeutic effect on DMN-induced hepatic fibrosis in rats through inhibiting liver inflammation and lipid peroxidation. Further studies are needed to confirm application of GAK on liver diseases in humans. The act of why high amounts of GAK was improved biochemical values compared to low or moderate levels that tested in this study; may be due to

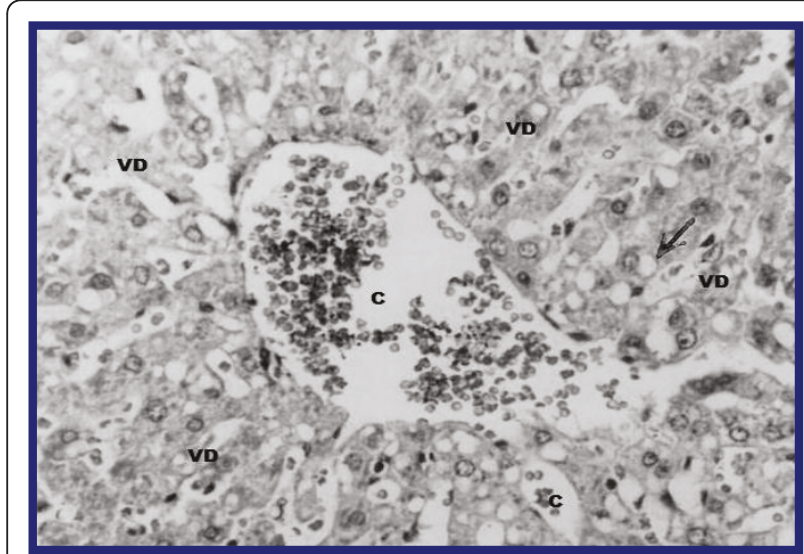

Figure 6 liver of rat DMN-injected (III) +GAK $(0.5 \mathrm{mg} / \mathrm{kg} / \mathrm{BW} /$ rat). VD: vacuolar degeneration observed in hepatocytes. C: congested sinusoids and central vein (Grade 1.5).

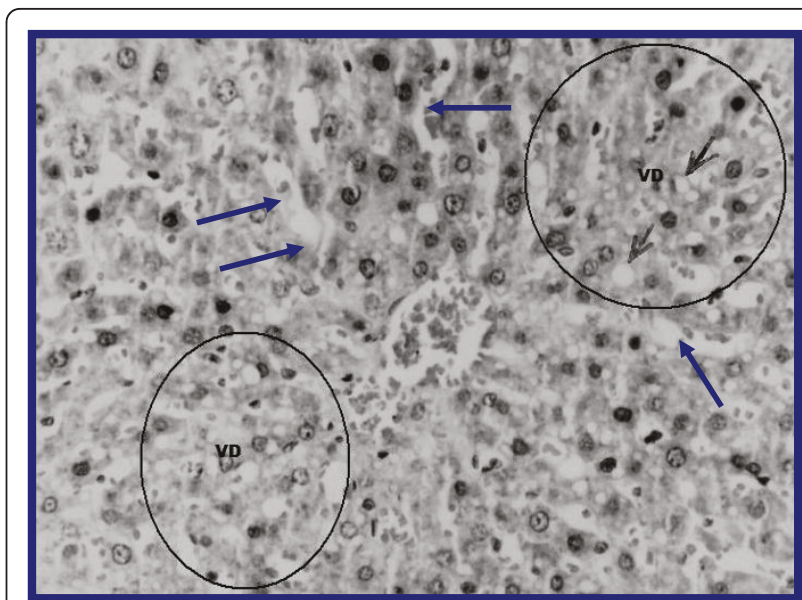

Figure 7 liver of rat DMN-injected (III) + GAK ( $1 \mathrm{mg} / \mathrm{kg} / \mathrm{BW} / \mathrm{rat})$ (Blue arrows): dilated and congested sinusoids, VD: hepatocytes showing vacuolar degeneration (Grade 2).

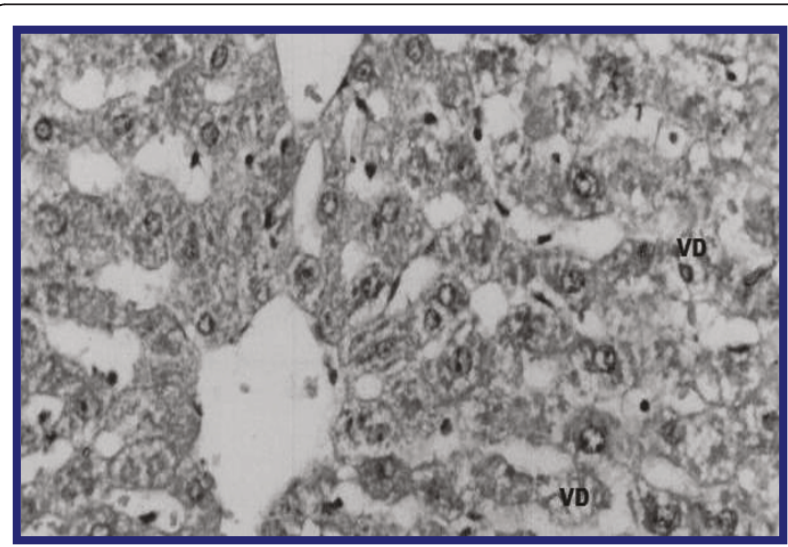

Figure 8 liver of rat DMN-injected (IV) + GAK (1.5 mg/kg/BW/ rat) (VD): Few vacuolar degenerated hepatocytes (Grade 0 ).

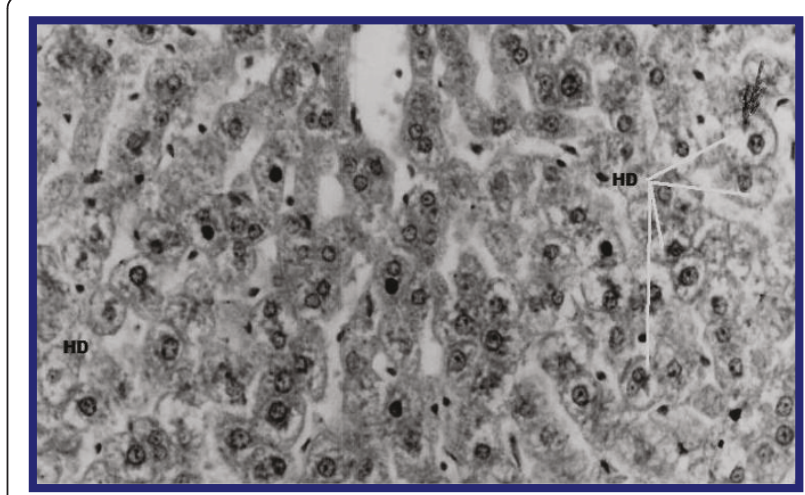

Figure 9 (Another section) Liver of rat DMN-injected (IV) + AKG (1.5 $\mathbf{~ m g / k g / B W / r a t ) . ~ R e l a t i v e l y ~ n o r m a l ~ h e p a t i c ~ a r c h i t e c t u r e . ~ ( H D ) : ~}$ Few hepatocytes demonstrate hydrotropic degeneration (Grade 0.5). 
increase levels of oleic acid and other polyphenols in apricot kernels. Due to apricot kernels research warning from toxicity of apricot kernels due to presence of cyanide; this study detoxified apricot kernels and fed them to rats on different levels. We would suggest that the dietary form of apricot kernels mixture which called "Dokka" that is eaten in Egypt as a part of Egyptian dietary practices may have a detrimental health effect according to the toxicity levels. On the other hand, Dokka usually mixed with several herbs such as coriander, sesame and salt that may offset the side effect of toxicity. Because of high levels of salt in Dokka the dietary intake is not consumed in high amount which means that has a little detrimental effect on health.

\section{Acknowledgements}

The author thanks Faculty of Medicine, Cairo University and Ms Wegdan A Rashad for very helpful discussion and encouragement and making the histopathological slides.

\section{Authors' contributions}

The author conceived, designed and coordinated the work, as well as prepared the manuscript and carried out analytical work and statistical analysis and approved the final manuscript.

\section{Competing interests}

The author declares that they have no competing interests.

Received: 2 June 2011 Accepted: 7 July 2011 Published: 7 July 2011

\section{References}

1. Garciaviguera C, Bridle P, Ferreres F, Tomasbarberan FA: Influence of variety, maturity and processing on phenolic. compounds of apricot juices and jams. Z Lebensm Unters Forsch 1994, 199:433-436.

2. Pedersen CB, Kyle J, Jenkinson AM, Gardner PT, MCPhail DB, Duthie GG: Effects of blueberry and cranberry juice consumption on the plasma antioxidant capacity of healthy female volunteers. Eur I Clin Nutr 2000, 54:405-408.

3. Abdel-Moemin AR: To investigate the antioxidant properties of dietary flavonoids in human metabolism [dissertation]. Belfast: The Queen's University; 2004

4. Gezer I, Haciseferogullari H, Demir F: Some physical properties of Hacihaliloglu apricot pit and its kernel. J Food Eng 2002, 56:49-57.

5. Durmaz G, Alpaslan M: Antioxidant properties of roasted apricot (Prunus armeniaca L.) kernel. Food Chem 2007, 100:1177-1181.

6. Femenia A, Rosello C, Mulet A, Canellas J: Chemical com-position of bitter and sweet apricot kernels. J Agric Food Chem 1995, 43:356-361.

7. Alpaslan M, Hayta M: Apricot kernel: Physical and chemical properties. J Am Oil Chem Soc 2006, 83:469-471.

8. Abd el-aal MH, Khalil MKM, Rahma EH: Apricot kernel oil: Characterization, chemical composition and utilization in some baked products. Food Chem 1986, 19:287-298.

9. Hacisefero ullari H, Gezer I, Özcan MM, Asma BM: Post- harvest chemical and physical mechanical properties of some apricot varieties cultivated in Turkey. J Food Engineering 2007, 78:364-373.

10. Holzbecher MD, Moss MA, Ellenberger HA: The Cyanide Content of Laetrile Preparations, Apricot, Peach and Apple seeds. Clinical Toxicology 1984, 22:341-347.

11. Suchard JR, Wallace KL, Gerkin RD: Acute Cyanide Toxicity Caused by Apricot Kernel Ingestion. Annals of Emergency Medicine 1989, 32(6):742-744.

12. Jones MB: Seasonal trend of cyanide in peach leaves and flower buds and its possible relationship to the rest period. Proc Am Soc Hort Sci 1961, 71:117-120.
13. Montgomery RD: Cyanogens. In Toxic Constituents of Plant Foodstuffs. Edited by: IE Liener. New York: Academic; 1969:143-155.

14. Seigler DS: Isolation and characterization of naturally occurring cyanogenic compounds. Phytochemistry 1975, 14:9-29.

15. Jukes TH: Is Laetrile a vitamin? Nutr Today 1977, 12-16,

16. Selby LA, Menges RW, Houser EC, Flatt RE, Case AA: Outbreak of swine malformations associated with the wild black cherry, Prunus serotina. Arch Environ Health 1971, 22:496-501.

17. George J, Rao KR, Stern R, Chandrakasan G: Dimethylnitro- samine-induced liver injury in rats: the early deposition of collagen. Toxicology 2001, 156:129-138.

18. Jézéquel AM, Mancini R, Rinaldesi ML, Macarri G, Venturini C, Orlandi F: A morphological study of the early stages of hepatic fibrosis induced by low doses of dimethylnitrosamine in the rat. J Hepatol 1987, 5:174-181.

19. Ming LC, Chang QY: Hepatic fibrosis. First published. Beijing: Beijing People's Medical Publishing House: 2008, 3-4.

20. Bissell DM: Hepatic fibrosis as wound repair: a progress report. J Gastroenterol 1998, 33:295-302.

21. Wasser S, Tan CE: Experimental models of hepatic fibrosis in the rat. In Ann Acad Med. Volume 28. Singapore; 1999:109-111.

22. Jézéquel AM, Mancini R, Rinaldesi ML, Ballardini G, Fallani Bianchi MF, Orlandi F: Dimethylnitrosamine-induced cirrhosis. Evidence for an immunological mechanism. J Hepatol 1989, 8:42-52.

23. El-Adawy TA, Rahma EH, El-Badawey AA, Gomaa MA, Lásztity R, Sarkadi L: Biochemical studies of some non-conventional sources of proteins Part 7. Effect of detoxification treatments on the nutritional quality of apricot kernels. Molecular Nutrition and Food Research 2006, 38:12-20

24. Waterman PG, Mole VH: Analysis of phenolic plant metabolites. Bioessays, Oxford: Blackwell; 1994:28:65-71.

25. Rezaul Haque M, Howard Bradbury J: Total cyanide determination of plants and foods using the picrate and acid hydrolysis methods. Food Chem 2002, 77:107-114.

26. Bradbury JH, Bradbury MG, Egan SV: Comparison of methods of analysis of cyanogens in cassava. Acta Horticulturae 1994, 375:87-96.

27. Pearson D: Chemical Analysis of Foods. Church Hill Living stone London; 71976

28. AOAC 2000, Eds: Official methods of Analysis 17th Association of Official Analytical Chemists.Edited by: Pearson, D. Washington, D. Ci , 12 1976:, Chemical.

29. Reeves PG, Nielson FH, Fahey GC: AIN-93 purified diets for laboratory rodents: final report of the American Institute of Nutrition ad hoc writing committee on the reformulation of the AIN-76A rodent diet. J Nutr 1993, 123(11):1939-1951.

30. Asakura S, Daimon H, Sawada S, Sagami F: A short-term assessment of tumor-promtion activity in the livers of rats treated with two genotoxic methylating agents: dimethylnitrosamine and methylnitrosourea. Toxicol Lett 1998, 98(3):155-167.

31. Chapman DG, Castillo R, Campbell JA: Evaluation of protein in food I: A method for the determination of protein and food efficiency ratio. Can J Biochem Physiol 1959, 37(5):679-686.

32. Reitman S, Frankel S: A colormetric method for the determination of serumglutamic oxalocetic and glutamic pyruvic transaminases. Am J Clin Path 1957, 28(1):56-63.

33. Yagi K: A simple fluorometric assay for lipoperoxide in blood plasma. Biochem Med 1976, 15:212-216.

34. Goth L: A simple method for determination of serum catalase activity and revision of reference range. Clin Chim Acta 1991, 196:143-152.

35. McCord JM, Fridovich I: Superoxide dismutase. An enzymic function for erythrocuprein (hemocuprein). J Biol Chem 1969, 244:6049-6055.

36. Paglia $D E$, Valentine $W N$ : Studies on the quantitative and qualitative characterization of erythrocyte glutathione peroxidase. J Lab Clin Methods 1967, 2:158-169.

37. Bancroft JD, Stevens A: Theory and practice of histological techniques. New York: Churchill Livingstone; 41996.

38. Steel RGD, Torrie JH: Principles and Procedures of Statistics: a Biometrical Approach. New York: McGraw-Hill,; 21980.

39. Shikata N, Oyaizu T, Senzaki H, Uemura Y, Tsubura A: Liver apoptosis after dimethylnitrosamine administration in shrews. Exp Toxicol Pathol 1996, 48:307-311. 
40. Oyaizu T, Shikata N, Senzaki H, Matsuzawa A, Tsubura A: Studies on the mechanism of dimethylnitrosamine-induced acute liver injury in mice. Exp Toxicol Pathol 1997, 49:375-380.

41. Nout MJ, Tuncel G, Brimer L: Microbial degradation of amygdalin of bitter apricot seeds (Prunus armeniaca). Int J Food Microbiol 1995, 24:407-412.

42. Turan S, Topcu A, Karabulut I, Vural H, Hayaloglu AA: Fatty acid, triacylglycerol, phytosterol, and tocopherol variations in kernel oil of Malatya apricots from Turkey. J Agric Food Chem 2007, 55:10787-10794.

43. Nakagami T, Nanaumi Tamura N, Toyomura K, Nakamura T, Shigehisa T: Dietary flavonoids as potential natural biological response modifiers affecting the autoimmune system. J Food Sci 1995, 60:653-656.

44. Cassidy A, Dalais FS: Phytochemicals. In Nutrition and Metabolism. Edited by: Gibney, MJ, Macdonald, IA, Roche HM. Blackwell Publishing, Oxford, UK; 2003:307-317.

45. Law M: Plant sterol and stanol margarines and health. British Medical Journal 2000, 320:861-864.

46. Gomez E, Burgos L, Soriano C, Marin J: Amygdalin content in the seeds of several apricot cultivars. J Sci Food Agric 1998, 77:184-186.

47. Shragg TA, Albertson TE, Fisher CJ: Cyanide poisoning after bitter almond ingestion. West J Med 1982, 136:65-69.

48. Franco RS: Regulation of antioxidant enzymes gene expression in response to oxidative stress and during differentiation of mouse skeletal muscle. Free Radic Biol Med 1999, 27:1122-1132.

49. Gaeta LM, Tozzi G, Pastore A, Federici G, Piemonte F: Determination of superoxide dismutase and glutathione peroxidase activities in blood of healthy pediatric subject. Clin Chim Acta 2002, 322:117-120.

50. Nielsen F, Mikkelsen B, Nielsen J, Andersen HR, Grandjean P: Plasma malondialdehyde as biomarker for oxidative stress: Reference interval and effect of life-style factors. Clin Chem 1997, 43:1204-1214.

51. Gerbhart R: Oxidative stress, plant derived antioxidants and liver fibrosis. Planta Med 2002, 68:289-296.

52. Halliwel B, Chirico S: Lipid peroxidation: Its mechanism, measurement and significance. Am J Clin Nutr 1993, 57:715-725.

53. Ergun S, Yontem M, Yerlikaya A, Ozata A, Uysal K, Kurt H: Influence of dietary oils on liver and blood lipid peroxidation. Saudi Med J 2005, 26(3):442-446.

54. Lu YF, Lu S: Influence of dietary fat saturation on lipid peroxidation of serum and low density lipoprotein in rats. Nutr Res 2002, 22:463-472.

55. Cline SD, Riggins JN, Tornalleti S, J Marnett L, Hanawalt PC: Malondialdehyde adducts in DNA arrest transcription by T7 RNA polymerase and mammalian RNA polymerase II. Proc Natl Acad Sci USA 2004, 101:7275-7280.

56. Venukumar MR, Latha MS: Antioxidant activity of Curculigo orchioides in carbon tetra chloride induced hepatopathy in rats. Indian J Clin Biochem 2002, 17:80-87.

57. Gajanan SG, Chatterii R, Bagga AS: Free radicals and human disease. Cardiothoracic J 1997, 3:31.

doi:10.1186/1476-511X-10-114

Cite this article as: Abdel-Rahman: Can apricot kernels fatty acids delay the atrophied hepatocytes from progression to fibrosis in dimethylnitrosamine (DMN)-induced liver injury in rats? Lipids in Health and Disease 2011 10:114

\section{Submit your next manuscript to BioMed Central and take full advantage of:}

- Convenient online submission

- Thorough peer review

- No space constraints or color figure charges

- Immediate publication on acceptance

- Inclusion in PubMed, CAS, Scopus and Google Scholar

- Research which is freely available for redistribution

Submit your manuscript at www.biomedcentral.com/submit 